\title{
Austerity, personalisation and the degradation of voluntary sector employment conditions
}

\section{Ian Cunningham, Department of Human Resource Management, University of Strathclyde, Glasgow, G1 IXQ}

This qualitative study of two social care organisations, explores how public sector austerity and policies to personalise social care services through introducing individual budgets in the UK combine to reshape employment conditions. It further explores how these new market relations impact on staff morale and commitment. The individual case summaries reveal a remarkable degree of similarity in terms of employment outcomes, with social care workers experiencing an erosion of the standard employment relationship. Workers experience greater insecurity in areas of pay and conditions, working time, training and development, career prospects, along with work intensification. Worker morale appeared vulnerable as employees struggled to cope with worsening working conditions, but also expressed concerns with quality of care in an era of austerity.

\section{INTRODUCTION}

This article is concerned with exploring how public sector austerity and policies to personalise social care services through introducing individual budgets are combining to reshape employment conditions in provider organisations in the voluntary sector, and how these new market relations impact on staff morale and commitment. Public funders have outsourced direct service provision to voluntary sector social services (VSSS) organisations through the application of principles of New Public Management (NPM) (Evans and Shields, 2002). Analysis of the employment outcomes from this outsourcing have revealed incidents of significant degradation in employment conditions in VSSS organisations (Cunningham, 
2008). Degradation has been seen to be more likely where there has been high levels of resource dependency on a single or only few funders by VSSS providers (Cunningham, 2008).

UK purchaser - provider relationships are currently an area of further interest as they are being reshaped under a policy regime of austerity and policies such as the 'Big Society'. The latter emphasises the VSSS role in reducing public expenditure while delivering more user-centred services. The move to more user-led services has been encapsulated in the term personalisation (Needham, 2012). These policy changes contain significant implications for employee conditions among providers (Bach, 2012).

Results from a comparative qualitative study of two voluntary providers are provided. The analysis finds how public expenditure cuts and personalisation threaten the long-term sustainability of organisations and the survival of standard employment relationships for workers. Such changes are accompanied by growing fears among the workforce concerning their future employment conditions and quality of care in public services.

\section{CONTEXT}

This section provides a short overview of the development of the quasi-market for care under New Public Management (NPM), and the emerging fiscal and policy challenges from the era of austerity and the personalisation of social care services in the UK. Since the 1980s public services in most industrialised countries have seen significant market-based reforms inspired by the principles of NPM. While acknowledging debates about its coherence, NPM has been a central influence in public service reforms in recent decades. NPM seeks to remove differences between private, public and voluntary sectors. This erosion of difference is undertaken through introducing competition and private sector management techniques in the delivery of public services. In addition, it emphasises the principles of 
efficiency, value for money and greater service user/customer choice (Hood, 1991: Bach and Bordogna, 2011). NPM also encourages participation of independent providers from the private and voluntary sectors to deliver services to vulnerable groups (Davies, 2011: Shields, 2014). Studies in the UK and Canada have revealed how for voluntary organisations participation on these terms has involved a re-ordering of their relations with the state. Specifically, there has been a requirement on the sector to be more pro-market embracing competition, that, in turn, has increased financial insecurity and undermined terms and conditions of employment (Baines, 2008: Cunningham, 2008: Cunningham and James, 2009).

These trends are mediated by a number of factors or characteristics among service providers, however. These factors include: the capacity of providers to exercise degrees of resource independence through multiple contracts; the refusal to tender for unsustainable work; and the development of niche market activities (Cunningham, 2008). At the same time, purchaser - provider relations are fluid and the former has been found to counter the efforts of the latter to sustain independence and employment conditions. This has been undertaken by: forcing providers to tender for unsustainable work as a condition of 'approved' or 'preferred' status in the market (Cunningham 2008: Cunningham and James, 2014); retendering services in order to wring further cost concessions (specifically in labour costs); and the introduction of new, cheaper private sector entrants into the market (Cunningham and Nickson, 2012).

\section{Austerity and the sustainability of the UK VSSS}

The continued exploration of purchaser - provider relations in outsourced social care services between local authorities and Voluntary Social Services Sector (VSSS) organisations in the UK is timely given there is a period of significant transformation underway. The 
sustainability of the VSSS is threatened in the aftermath of the global financial crisis (Shields, 2014). The UK suffered considerably from recession with significant falls in output and a large fiscal deficit. The Conservative led coalition government's priority is to cut this deficit so that public expenditure returns to levels not seen since the 1930s (Bach, 2012).

Despite the devolved Scottish Government's desire to build a social democratic alternative to the neo-liberal social policy of the UK government (Danson and Whittham (2011), for the immediate future that goal continues to be undermined by coalition spending priorities and the influence of Conservative-led ideological considerations. In particular, the coalition have encouraged the themes of small government and shrinking the state through the policy of the 'Big Society'. The policy is seen as building on New Labour's efforts to move the non-profit sector from the periphery of social services provision to the mainstream, where voluntary organisations increasingly directly provide public services. The Coalition's agenda is influenced by the critique by Phillip Blond (2010) of New Labour and Thatcherism in allowing a concentration of state and market power respectively in the provision of services. Here, Thatcherism is seen as failing to take account of market failures and having an over-emphasis on cost savings in service provision. New Labour in contrast was seen to be overly reliant on state solutions to social problems, leading to increased welfare dependency. The alternative according to Blond (2010) is to empower local communities and thus enable people to take more personal responsibility in their lives (see Bach, 2012 for summary). The Big Society encourages service delivery that is outsourced to local communities, with an emphasis on the contribution of voluntary activity (Lowndes and Prachett, 2012). The implementation of the initiative has met with considerable controversy. Strong new right individualism and distrust of the state is seen to be present in the Big Society agenda (Lowndes and Prachett, 2012). Further, it is questioned whether it represents a real radical reforming measure regarding the relationship between state, society and the individual, or 
mainly a device to legitimise the aforementioned cuts in public expenditure and VSSS funding (Sage, 2012: Bartels and Cozzi, 2013). Others see it as part of a neo-liberal assault on welfare via reducing local government services through outsourcing, job losses and pushing down the value of social labour while exacerbating existing gender inequalities (Levitas, 2012).

Recent audits of the Big Society point towards a gap between its rhetoric and reality. Specifically, a significant number of voluntary organisations are struggling to survive because of rising demand, which is only partially met by falling government income. Further dramatic cuts to sector income are anticipated over the forthcoming years, threatening closure of much needed services to the vulnerable. In comparison to the rhetoric regarding greater sector involvement, much of the large public service contracts have gone to large private organisations that have subsequently subcontracted small parcels of provision to VSSS providers (Civil Exchange, 2013).

This is in parallel with concerns over future cuts given UK local authorities (VSSS main funders) are at the forefront of public expenditure savings. Public service retrenchment demanded spending reductions from authorities of 27\% between $2011-2012$ and $2014-$ 2015 (Bach, 2012: Lowndes, Pratchett, 2012). Moreover, $£ 4.5$ billion of expenditure cuts were imposed on the voluntary sector by 2012 (Sage, 2012). Such cuts are seen as undermining any real chance of achieving the mainstreaming VSSS provision in social care as innovative and specialist services by the sector require significant investment which so far has only come from the state (Sullivan, 2012).

The personalisation and individualisation of services is also key to the Big Society agenda, and originates from New Labour's goal of encouraging service users to become key actors in reshaping public services (Bach and Kessler, 2012). Personalisation seeks to tailor public services to individual user (or customer) needs. Users are supposed to have a direct say 
in the planning and delivery of their service. In social care personalisation is operationalised throughout the UK through the provision of Direct Payments (DPs) and Individual Budgets (IBs).

This new funding regime potentially generates a significant degree of uncertainty and risk among VSSS providers of services and their workforces. For example, greater uncertainty is created through the devolution of funding to individuals enabling them to choose and switch providers/carers if dissatisfied with service (Leece, 2010). Personalisation is also part of the Big Society's objective of a smaller state (Bach, 2012), with local government at the heart of such efforts. The policy can be used by local government as another mechanism to generate savings and uncertainty among VSSS providers and their workforces. Local authorities can implement cuts in public expenditure through individual budgets and DPs by influencing the pace of change and conditionality and eligibility that set the framework for determining access to and the nature of services, or simply through efficiency savings gained from their power over the level of expenditure allocated to various forms of individual budget (Ellis, 2007: Duffy et al, 2009: Needham, 2011). VSSS providers and their workforces are vulnerable to such cuts as the majority of users who switch from having services funded through traditional local authority block contracts to DPs and IBs will remain with existing providers (Baxter, et al, 2010).

This link between austerity and personalisation is just as relevant in Scotland, especially given the move to DPs in social care services has been given a significant statutory boost through the introduction of the Self-Directed Support Act 2012 (Cunningham and Nickson, 2012). Moreover Scotland has to play its own part in deficit reduction programmes by implementing cuts in local services.

Information on the precise impact on provider organisations and their workforce conditions operating in these newly created individualised markets remains limited. This 
article asserts that such changes potentially introduce further insecurity (or marketisation) of employment relationships in the VSSS. Marketisation is acknowledged to be a process whereby the features of the traditional standard employment relationship of secure employment, collective pay and conditions, regular patterns of working hours, training and identifiable career paths (Rubery and Urwin, 2011) are eroded and replaced by less secure forms of employment status, including part-time and temporary work. Such marketisation in social care is generated under austerity and personalisation through a combination of exposing workers to the risk of losing their job as users move on and shrinking income from a reduced public service resource base.

Current debates surrounding marketisation and employment are divided as to whether a sea change is occurring in the UK and US (Capelli, 1999: Sennett, 1998: McGovern, et al, 2007). The debate, however, does recognise the vulnerability of workers in outsourced workplaces such as the VSSS as having a greater likelihood of experiencing a marketisation of their employment conditions (Flecker et al, 2009), and that those experiencing greater insecurity also face work intensification (McGovern, et al 2007).

In other studies, dominant purchasers have forced outsourced social care organisations to provide only basic coordinating and protection functions for staff. This meant the erosion of the standard employment relationship for social care workers (Rubery and Urwin, (2011). Similarly, reports in the UK of care providers breaching minimum wage laws and increasingly relying on zero hours contracts blamed on procurement and tendering practices by funders confirms this pattern of employment degradation (The Resolution Foundation, 2013).

This article seeks to redress this limited knowledge regarding the impact of austerity and personalised/individualised forms of funding on outsourced providers and on the terms and conditions of employment of their staff. It also seeks to explore whether previous 
strengths among providers such as more diverse patterns of resource dependency can limit the impact of the financial shocks of austerity on employment conditions.

Finally we know little regarding worker reactions to the above changes. In terms of employment, collective resistance has been apparent in voluntary social care settings where terms and conditions have been under threat (Simms, 2007: Hemmings, 2011). Individual forms of funding represent a further stage in the commodification of care. In such circumstances, the workforce may be providing their labour in care settings where the intrusion of a state sponsored, alien market ideology conflicts with their own values, again leading to resistance (Thompson and Bunderson, 2004).

\section{METHOD}

This section provides a short summary of the conceptual framework and method undertaken in this study. This article firstly explores how public sector austerity and policies to personalise social care services through the funding mechanism of individual budgets are combining to reshape employment conditions in VSSS organisations. Secondly, it investigates how these new working conditions impact on staff and their morale and commitment. The study identifies austerity and personalisation as forces that potentially erode the standard employment relationship for workers in outsourced VSSS organisations. The influence of these forces manifest in the reduced resources from local authority funders passed on through Direct Payments and Individual Budgets; local authority control over eligibility for services; and the power of the service user to switch provider. It further considers the influence of factors such as differences in resource dependency, and union interventions (Cunningham, 2008) as possible variables that may limit these changes, or cause possible variation between organisations. 
The research involved in-depth, comparative qualitative case study research in two VSSS organisations. The case study method was chosen as it lends itself to investigating complex social phenomena (Yin, 2014). In this case, it brings the benefits of allowing a rich, in-depth exploration of voluntary sector employment relations within the distinct socioeconomic and political environment of economic austerity and public service reform under personalisation. The case study approach comprised of collecting secondary data concerning organisational mission, and HR policies within the two cases. The main data collection method comprised of semi-structured interviews (34 in total) conducted with senior and line managers, employees and their representatives.

Voluntary 1 has a relationship with a single funder. Voluntary 2 had a relationship with 7 local authorities. Organisations were selected because of their current efforts to introduce personalisation policies. Moreover, they were also chosen on the basis of their different patterns of resource dependency, with Voluntary 1 being potentially the more vulnerable to facing cuts and pressure to marketise employment conditions. Table 1 outlines respondents in the study. Single interviews were conducted with each person. Management respondents within the cases were selected on basis of having oversight of the strategic operational and HR response to austerity and personalisation. Questions were focused on changing organisational HR policies resulting from austerity and personalisation. Employee respondents were selected purposely with regard to their experience of working within projects that were introducing more personalised approaches to service provision. Questions focused on reasons for working within the sector; their awareness of organisational context; changes to working conditions and services; and their attitudes to these changes and their continuing level of organisational commitment. Interviews from each set of data were transcribed verbatim. 


\section{Insert Table 1 here}

The findings begin with a summary of the context of each case, followed by the impact on employment conditions. In the latter case, the focus of analysis is specifically on job security, pay and conditions, working hours, training and development, and career progression and employee responses to such changes. For the purposes of comparison Table 2 reveals the employment outcomes within each organisation.

\section{FINDINGS}

\section{Insert Table 2 here}

\section{Voluntary 1}

Voluntary 1 was a medium-sized provider delivering a range of community based mental health services. These services focused on prevention of an escalation in mental health conditions among users, with the aim of eventually achieving recovery. Workers were historically engaged at Senior Support Worker and Support Worker grade in the community delivering support, advice and counselling to users regarding domestic issues, or more sophisticated support. As will be shown these staff grades were increasingly under threat. The organisation had also developed several community-based group centres seen as a step towards ending isolation among its user group.

\section{Purchaser-provider context}

Voluntary 1 had one main local authority funder - a relationship that had positive and negative aspects. It was claimed that on the whole there was a history of efforts on both sides 
to build and sustain a 'partnership' through recognition of mutual goals in relation to helping the local authority discharge its statutory duties and strategic priorities in mental health. Management in Voluntary 1 felt these duties and priorities were strongly aligned with the organisation's own mission and values. The local authority was initially seen as being paternalistic in its approach to the relationship through the provision of advice on services and employment issues.

Over the preceding twelve years, NPM's influence had grown as Voluntary 1 reported it had to be more accountable for services delivered as local authority control was exercised via performance indicators and legalistic contracts. Other NPM familiars included the gradual reluctance of the authority to pay for anything that was not direct service provision, making it difficult for Voluntary 1 to continue participatory practices such as supervision, and joint planning forums between management, staff and users. In addition, it was usual that uplifts in funding would be below inflation, leading to the search for organisational efficiencies, while demand for services was rising.

Efforts to control Voluntary 1 by the local authority could on occasion influence matters such as staffing levels and skills mixes in particular projects.

If you come more and more to rely on one main funder sometimes you get the feeling that the local authority is almost like a shadow Director on your board (CEO, Voluntary 1).

Indeed, Voluntary 1 had a local authority official on its governing board: reflecting its earlier history when such a representative was present in an advisory capacity. In the current era of austerity this presence was proving to be controversial as other board members and the 
organisation's management team felt there was a conflict of interest, as the individual enthusiastically embraced the agenda of cuts forced on the organisation by the authority.

Financial austerity meant Voluntary 1 experienced successive funding cuts (on average by 4 percent p.a.) from 2008, while still being asked to deliver the same number of hours of services. From 2012, respondents reported particular problems with how the authority linked austerity measures to personalisation. Individual budgets and accompanying introduction of market forces were being used to reduce the number of providers and drive down costs in the mental health field. Cost savings among providers were achieved through the enforcement by the authority of an hourly rate for services that was part of a new commissioning framework. Acceptance of this hourly rate would lead to the council placing Voluntary 1 among its approved providers, while leaving other organisations that were unable to adjust outside of this list. Attainment of approved status was crucial for organisational survival as the authority recommended DP holders to buy services from only providers on the list.

Although this new rate would be phased in, respondents felt that the authority anticipated it would be significantly lower than Voluntary 1's current rate - approximately 20 percent less. This linking of austerity measures with personalisation affected the organisation's financial security, sustainability and survival. Voluntary 1 had to subsidise the new rate through its organisational reserves. There were also concerns regarding dealing with potentially hundreds of customers with individual budgets, compared to one block contract. Particular problems were anticipated in terms of the planning of individual care packages and ensuring each budget was adequate enough to meet need. There were also worries regarding the implications of non-payments on financial security and relations with users when attempting to recover arrears. 
The following sections will now outline the employment implications of this environment within Voluntary 1.

\section{Job security}

Historically, from the early 2000s the cost and efficiency aspects of NPM had led to successive cuts in management posts, so that the organisation employed only three senior managers. Those remaining had absorbed numerous functions from departing managers. Such was the 'leanness' at senior management level that they increasingly had to rely on the expertise of the governing board or non-paid advisers in the areas of finance, marketing, operations and HR.

These remaining senior managers identified emerging problems with job security across the workforce stemming from the new environment of austerity and personalisation. Cuts had led to the closure of two of its services, leading to redundancies. Jobs were also under threat due to changes in the hourly rate. The aggregate value of DPs in services meant that there were not sufficient resources to fund all workers currently employed at Senior Support Worker level. These workers were re-interviewed for their posts and those who were unsuccessful faced redundancy or demotion: the latter involving a cut of approximately $£ 4,000$ in salary. The introduction of across-the-board financial charges for services and the tightening of eligibility criteria by its funder were also reportedly leading to fear and uncertainty among users, and doubts over whether they would retain their service with the organisation.

This insecurity among service users fed further workforce anxiety about their job security. Specifically, workers feared that users, already beginning to feel the pain of benefit cuts from austerity, would be reluctant or unable to access services that were subject to charges, thus threatening jobs. In addition, tightening eligibility criteria meant that some 
users would be unable to continue accessing services, again threatening jobs. Respondents contrasted the situation with previous funding regimes that were characterised by block funding. This type of funding although inherently unstable because it only gave security for at most two - three years was seen by workforce respondents as preferable to the emerging regime of personal budgets, charges and shrinking eligibility.

\section{Pay and conditions}

Up until 2008, the regulatory reach of collective bargaining from public sector unions was apparent. Voluntary 1 followed public sector negotiated rates of pay. The CEO commented ruefully:

The Director of Social Work when we started doing community care work wrote to us saying 'Please reassure me that your terms and conditions of employment as you begin to develop your services are consistent with those of the local authority'.

From 2008 and the start of the financial crisis the organisation was unable to provide a cost of living pay rise undermining its ability to award comparable rewards to those received by public sector workers. The working week had also been increased from thirtyfive to thirty-seven and a half hours, and one day of annual leave had been removed.

The aforementioned changes to the organisation's hourly rate was leading to further pressure on terms and conditions as the Head of Social Care from the local authority called for greater flexibility in terms and conditions. The financial climate imposed by the local authority led to Voluntary 1 implementing a five percent pay cut across the board; a loss of two further days of annual leave (with no compensation); and the extension of the working week from thirty-seven and half hours to thirty-nine. The demise of block contracts was also 
anticipated to lead to the removal of some financial cover for sick pay. Previously block contracts contained financial provision for estimated sickness absence in the workforce, while direct, individualised funding to service users contained no such support. Subsequently, management was beginning to consider how to cope with such change "without penalising the people who are genuinely unwell' (Senior Administrator).

Collective resistance from within Voluntary 1 was limited. The union representative reported an increase in membership from $70-80$ percent density in response to the worsening climate. Attempts to take action (beginning with a strike ballot) were fruitless, however, as a combination of reluctance to disrupt services and a perception among staff that nothing could be done because they had no power to alter decisions made by the local authority, meant few supported it.

They have nothing to negotiate with. What can you negotiate with when a company has had to slash its budget? How can they turn around and fight on your behalf? (SW, female).

Other respondents expressed frustration at how work colleagues accepted the changes, and the lack of any union activism. The union representative followed the ballot with efforts to undertake a consultation process with the employer to mediate the worst excesses of the restructuring with the aid of a full-time official. Moreover, with the support of senior management this full-time official reportedly used the organisation's case as part of a wider union campaign to highlight austerity cuts and the link to local authority personalisation programmes. The full-time official also reportedly worked closely with management to ensure consultation and selection of those for redundancy was within statutory guidelines. 


\section{Working time}

The organisation had generally established a pattern of working hours that had allowed the workforce to either work full or part-time depending on their preferences. Austerity and personalisation brought a much more uncertain financial and operational position so management respondents reported that in the future the organisation could no longer guarantee a standard pattern of full-time hours of work. Respondents therefore anticipated a proliferation of different employment contracts, including 'zero-hours'. Several new recruits were recently employed on contracts ranging from a minimum of five, ten and sixteen hours, with no guarantee of an established geographic location within which they would be working.

\section{Training and development}

Over the preceding years there had reportedly been direct efforts by the local authority to influence matters such as staffing levels and skills mixes in particular projects run by Voluntary 1. It was, however, the indirect consequences of funding constraints that were now influential. Voluntary 1 had gradually run down its training function in the face of emerging austerity. The Training Manager was made redundant as a consequence of restructuring several years previously and her functions were transferred to a senior administrative manager. Difficulties were also emerging because of the cut in the hourly rate by the local authority. Block grants had contained 2.5 percent for training purposes but there was now a great deal of uncertainty about future resources because of the proliferation of DPs that on aggregate provided less funding. It was also uncertain whether DP holders would be prepared to allow a proportion of their budgets to be allocated to pay for specific statutory training. 
These tensions were in the face of contrasting pressures on skills and training. Some of the newer people accessing services through DPs had extremely complex needs that workers had to cope with, e.g. multiple diagnosis such as mental health and intellectual disabilities. Employees also required a degree of up-skilling to deal with requests by people accessing services regarding negotiating the complexity of the DP system and helping them record outcomes. Some employees welcomed such developments as an opportunity to progress and receive personal development while helping service users. Yet management in Voluntary 1 claimed that financial pressures meant it had to introduce a whole new grade of staff at Support Assistant (SA) level with lower pay, skills and training, rather than the organisation's usual approach of employing people as Senior/Support Workers.

The aforementioned redundancies and demotions among Senior Support Workers was another clear indication of reductions in opportunities for progression in this organisation. Career paths were further undermined as the organisation's local authority funder was questioning the sustainability of front line posts with job titles such as Team Leader and Section Leader that normally reflected greater seniority and experience. In this case, although the actual positions were seen as necessary, the authority was insisting these titles were removed so that it was not seen to be wasting public funding on layers of management, and so 'denying these individuals the dignity of having their experience reflected in their job title' (CEO, Voluntary 1).

\section{Worker morale and commitment}

Workforce morale was being affected by a number of the above changes. For example, some employees exhibited a philosophical rejection of the commercial aspects of the personalisation agenda. 
It's the one thing that's actually making me think of changing my career. I am not here to talk to people about money...I've worked in mental health since 1979 and I was saying to a friend 'oh this just isn't for me' (SW, female).

Others were distressed with having to collect charges and arrears from service users, or objected to the commercialisation of care through the introduction of DPs.

Further problems with morale were centred on changes that involved perceived deskilling. Some workers despaired at the general drift towards deskilling among the care workforce.

I don't think that (training) is an issue, I don't think people will have any difficulty taking on the role. It's just whether it's a valuable genuine role to have (SW, female).

Part of what workers perceived to be deskilling and under-utilization of their particular skills set was linked to the new focus on the individual user. Several Senior Support Workers and Support Workers reported how being matched with an individual user involved intensive one-to-one support focusing on their needs, including personal care. These respondents felt this work took them away from what they perceived to be the more skilled traditional group activities practised in the organisation. In addition, the involvement in personal body care was seen as work more suited to Support Assistants. In this context, several people were leaving Voluntary 1 because of a perception that their skills would no longer be fully utilized, as they saw the combination of austerity and personalisation undermining previous standards of care.

In addition, concerns regarding job insecurity and cuts to pay and other conditions were having a detrimental impact on attitudes. 
There is generally a low feeling among people about what the future holds because there is so much uncertainty. We hear about changes to terms and conditions now that is what worries people ( $\mathrm{SW}$, male).

Working time was also an area of increasing tension especially the introduction of split shifts to cover fragmented services.

People need a work-life balance, and in this job that can be really tough to achieve, because a lot of shifts clash and people will just flatly refuse to have casual workers, which presents difficulties if there is illness, you would sometimes get there's no other option but to do an $8.00 \mathrm{pm}$ until 9.00am shift in the morning and then have nothing and then start as a sleepover at half three (SW, male).

At the same time, front-line respondents from Voluntary 1 emphasized how this did not lead to any lack of effort or commitment to providing services, and led to some 'trying to keep a face on because they know service users get upset if they get any hint that they're going to lose a service' (SW, female).

Any frustrations regarding compromises over work-life balance were tempered by a degree of relief among respondents that they remained in work while others in the organisation or in the wider sector lost their jobs.

\section{Voluntary 2}

Voluntary 2 was a multi-service provider dealing with adults with mental health problems, issues relating to alcohol and drug dependency and some with intellectual 
disabilities. It employed a mix of higher paid Support Workers and lower paid Support Assistants. Workers delivered a range of community and residential/supported accommodation services.

\section{Purchaser - provider context}

Voluntary 2 reported a similarly challenging financial environment to Voluntary 1, where an initial expansion of spending in the early to mid-2000s described as 'a little season heaven' (Senior operational manager) was followed by tightening budgets and then the impact of the financial crisis. Over the four - five years prior to the fieldwork the organisation had lost approximately $20-25$ percent of its turnover ( $£ 3 m-£ 4 m)$, while being asked to deliver the same amount of services by its funders.

There's no spare capacity now. I've been involved in the voluntary sector for thirtyfive years and this is without doubt the worst. In fact the period of Thatcher where everybody says 'oh Thatcher was awful' this is much, much worse in terms of its severity, the extent of it and the time of it (CEO, Voluntary 2).

Relations with funders were reportedly becoming more problematic with authorities increasingly focusing on the 'bottom line' rather than service users. The organisation was losing money, leading to internal debate regarding the sustainability of some projects. Indeed, Voluntary 2 was conducting negotiations with three local authorities regarding deficit funding of its services.

Management in Voluntary 2 also highlighted the inevitability of personalisation being linked by local authorities with cuts in expenditure over the forthcoming three - four years. It was anticipated that all authorities would, on average, cut the amount of funding to service 
users through DPs by between 10 - 15 percent, threatening an equivalent cut in organisational management costs and, again, the sustainability of services.

There were also deep concerns regarding how far the focus on cost would push down quality so that all organisations in the sector would become 'generic' providers. That is, organisations, previously delivering niche services through skilled workers, would only be funded to deliver a minimum standard of care according to what the local authorities deemed affordable. In this way the differences between organisations, their services and the skills of their workforces would erode. Providers would move towards employing increasing numbers of lower paid, skilled staff (Support Assistants) delivering common basic services.

It's all about money. We can talk about our principles and why we were there, but how many really work to that anymore? We've all introduced lower grades of staff, we've all asked people to work more, we've not paid cost of living increases. You can go to us, you can go to xxx, we both charge you twelve quid, they both employ lots of part-time staff that they can't afford to pay a decent wage (HR respondent).

\section{Job Security}

In direct response to local authority cuts, the weight of job losses fell predominantly on management grades leading to the loss of 50 posts. The organisation was also moving to downsize the numbers of Support Workers and replace them with Support Assistants. Further 'leanness' was achieved through the removal of all administrative staff from projects. Indeed, the CEO had to undertake basic admin work, and even did spells 'on-call' to cover twentyfour hour services. Moreover, Voluntary 2 had introduced a Voluntary Redundancy Scheme with the anticipation that it would lead to the loss of some 40 front-line post. Personalisation was also increasing a sense of job insecurity in Voluntary 2 as reassessments of client need 
by local authorities meant reductions in service user hours of support, which led to doubts regarding how many staff would be retained in services that suffered such cuts.

there is talk of service users' budgets getting slashed down the middle, so that's going to be two staff members, or one and a half staff members' jobs. So you don't feel safe (SA, female).

Among other workers there was also an emerging realisation that insecurity was increasing because of the possibility that people accessing services could move on or recover There was also some evidence of austerity blurring the boundaries between paid and unpaid work as cuts by authorities meant that there was little or no resource left for social outings. As a result, the organisation was piloting a scheme for volunteers to take over this work from paid staff.

\section{Pay and conditions}

In Voluntary 2, because of its aforementioned fall in turnover, the organisation had not been able to provide a consolidated rise in pay since 2008. In 2010 it underwent a pay and conditions review which led to an increase in the working week, the introduction of "waiting days' for sick pay and changes to maternity allowances. The organisation had also moved from a final salary to a career average pension scheme. These changes to pensions were not sufficient to achieve the desired saving, however, and the following year members were consulted regarding further additional contributions. Personalisation and the expansion of DPs that were part of austerity measures brought continued uncertainty over terms and conditions. In particular, the HR respondent was concerned whether the organisation could 
continue to sustain uniform rates of pay for staff when the value of DPs in each of its local authority areas would be subject to cuts and vary in value.

I am not sure how much of an impact the individual budgets are going to have on the terms and conditions we have now...I can see the possibility of fragmentation of pay grades, but I don't know if that's going to become a reality (HR Respondent).

Again, as in Voluntary 1, the union response was reportedly limited with efforts to intervene further hamstrung by low union density, which was approximately 25 percent.

\section{Working time}

Changes to working hours were also contentious. Local authorities were forcing a reconfiguration of working time on Voluntary 2. Reassessments of clients' needs meant care packages that previously lasted a full day were split into two or three hour blocks at the beginning and end of the working day. These reconfigured care packages were staffed through utilizing split shifts among established workers and more casualised employment contracts for new starts. Management, albeit reluctantly, also viewed the move to further casualisation of the workforce as inevitable.

These changes were not without problems. Rotas and supervisions were reportedly difficult to organise. Moreover, the HR manager and senior operational manager reported that even at a time of recession and high unemployment, Voluntary 2 found it difficult to recruit people on zero hour contracts, and it was feared that there would be minimum loyalty among those appointed on this basis. 
Management expressed concerns regarding training and development. The

CEO reported how, like many other organisations faced with recession, training and development budgets 'are always the first to go'. Restructuring as a consequence of austerity had led to a previously well -staffed (eight posts) learning and development function being reduced to two training officers. The organisation was also requiring its workforce to make a contribution to funding their own statutory training. Voluntary 2 was also struggling to meet the training needs of its pool of casual staff beyond the statutory minimum requirements.

This was further aggravated by austerity measures leading to cuts in line management roles, so lower skilled staff were being supervised by fewer managers. As with Voluntary 1, this delayering meant prospects among support staff for career progression to a supervisory role were limited.

This run down in training and reduction in management grades had the potential to impact detrimentally on service quality. The shortage of training resources was occurring in the face of management reports of how the organisation was recruiting from a pool of prospective employees who were of a poorer calibre than those entering care five years previously. A senior operational manager also highlighted how he was uncomfortable with the removal of so many managers as the lack of oversight and supervision may lead to abuse and poor practice among front-line staff. There were in addition emerging concerns regarding the impact on care standards, with one recent inspection leading to the regulator noting that the organisation was not providing the same level of training input into staff, and so downgraded service from an 'Excellent' rating to a 'Very Good'.

\section{Worker morale and commitment}

The HR Director in Voluntary 2, indicated how for the first time it's most recent staff survey revealed growing dissatisfaction with pay and conditions. Worryingly, senior 
management representatives added that they felt the organisation had gone about as far as it could go in terms of any further cuts for fear of the impact on workforce morale.

You are encouraging people to make choices under personalisation, but predominantly that is going to be provided by social care staff and because of costs that is going to be people coming in at Support Assistant level. You are then expecting them to function at quite a sophisticated level...That is an awful lot you're expecting off somebody who is on 12 or 13 grand a year (Service Manager).

This unease was confirmed by reports among workers of many of them struggling financially because of the lack of cost of a living rise for several years. Work intensification through cuts in holidays, and additional hours with no extra pay were other issues of particular discontent for some employees.

Job security was a key source of concern among workers. This was a reflection of recent job losses and news of the forthcoming voluntary redundancy programme. Moreover, increased emphasis on service user choice and the risks of users leaving to go to another provider added to feelings of insecurity. Finally, some indicated that they were afraid to build up too many days sickness in case this put them first in line for selection for redundancy.

Tensions were also emerging over changes to working hours as workers spoke of a mismatch of expectations between organisations, their rights as staff and the demands of people accessing their services. The latter were anticipating events and activities in the community outside of what was previously considered to be the normal working day. In response, management were moving towards demanding working patterns and staff attendance that could be classed as 'unsocial'. Workers were increasingly uncomfortable with 
these management demands, because they raised issues regarding their own work - life balance.

You're trying to say, there are limitations. The staff have rights as well. We're not your mum and dad or your family, we don't live here (SW, male).

The respondents were again particularly concerned with the introduction of split shifts, and how their days were increasingly broken up with periods of time of inactivity, with no time to return home because of poor public transport.

Workers did recognise the damage inflicted on services from these fragmented care packages. Respondents bemoaned the lack of opportunity to meet and discuss issues of service quality with over-stretched supervisors and line managers. Workers realised changes to services reflected cuts and employer efforts to resource reduced and fragmented packages of care whilst ensuring employees had sufficient hours of work. Periods between these worker interventions in people's homes, were reportedly characterised by increasing isolation of users as the resources for social activities in day centres were cut. This recognition in turn led to workers establishing informal social events, sometimes in their own time to make up for cuts in services and minimise emerging tensions between staff and users.

He used to go to the cinema twice a week, but now that's been cut to once a week. It's very hard to get through to him that it's not us and he can be a bit moody with staff because of this, which is a shame because obviously you're used to all these social hours and then all of a sudden they're cut right down (SW, female).

\section{DISCUSSION AND CONCLUSION}


This article has explored how public sector austerity and policies such personalisation are changing employment conditions in voluntary sector organisations, and the subsequent impact on worker morale. These questions are addressed in an era where the UK government advocates a shrinking role for the state through continued austerity and the related 'Big Society' project (Alcock, 2012: Danson and Whittam, 2011). The VSSS is identified as a key mechanism to implement such change (Bach, 2012). This agenda is influential even within the devolved administration of Scotland as local authorities and VSSS providers wrestle with successive draconian public expenditure rounds. This is at a time when the same devolved administration is committed through new statutory measures to deliver better quality services through greater user choice in service under personalisation.

In addressing the first of this study's objectives, each case reveals how the above policy arms are closely intertwined as personalisation has become a key tool in making cuts under austerity programmes. Subsequently, Table 2 and the individual case summaries reveal a remarkable degree of similarity in terms of employment outcomes, with social care workers experiencing an erosion of the standard employment relationship (Rubery and Urwin, 2011). Moreover, it further confirms how those subjected to such insecurity in employment, also experience work intensification (McGovern, et al, 2007) in this case through loss of holidays, the extension of the working week for the entire workforce and expansion of spans of control for senior and line management surviving programmes of restructuring and delayering.

The factors driving greater workplace insecurity are identified as local authority cuts in the value of individual budgets, restrictions to access to services and charges, and the uncertainty linked to capacity among users to switch providers. In the latter case, the study also identified how resources for training provision could also be subjected to greater uncertainty because of the growth of user choice. 
The degree to which organisations that are subjected to outsourcing exhibit greater degrees of vulnerability to these pressures (Flecker, et al, 2009) remains difficult to accurately ascertain given austerity is driving down the social wage through similar changes to terms and conditions even among those directly employed by the state (Bach, 2012). Nevertheless, findings from this study suggest outsourced providers and their workforces may face more difficulties in trying to recover this lost ground once economic growth is firmly established. Significantly, the influence of factors that traditionally ameliorated the impact of forces that erode the standard employment relationship in the VSSS such as diverse resource dependency (Cunningham, 2008) appear to be diminishing. The case of Voluntary 2 revealed similar patterns of insecurity and work intensification to Voluntary 1 . This suggests that austerity may be undermining the previous advantage held by organisations with multiple funders. Moreover, the possible common move to generic care provision by organisations, and the hiring of more unskilled staff suggest further evidence of a blurring of the boundaries between previously distinct types provider. Coupled with the weakness of unionisation in the sector, the chances of recovering all or even some of the lost ground in terms and conditions compared to those in direct employment by the state look slim. Further case comparisons need to be undertaken before we can generalise this finding, but the evidence suggest that austerity and the move to personalisation represent an intensification of marketisation pressures on the non-profit sector and its workforce.

Worker morale in this context appeared vulnerable. The majority of employees across both cases felt a growing unease concerning changes to their pay and conditions, working time and opportunities for skills development. A small minority of employees $-2-3$ from each organisation, objected to what they saw as the commercialisation of care through personalisation and individual budgets. However, caution has to be applied again before we can generalise from this latter finding, but it would be useful to conduct further research in 
this area of employee opinion. Another finding of interest that needs further investigation is the various links to erosion of service quality from the combination of pressures of funding cuts, increasingly lean operating conditions, deteriorating working conditions and problems with worker morale.

The above results pose questions regarding not only the sustainability of VSSS organisations in the market of care, but the rationale behind the outsourcing of social services. If providers left the market or went out of business, questions arise as to what would replace them? One option, is that in an era of individual users with personal budgets, provision of care would be left to a market of self-employed Personal Assistants (PAs), supplemented by volunteer activity. Another option is the increasing presence of cheaper private sector providers. Each option raises doubts regarding quality of care. PAs in the UK remain largely unregulated. The sustainability of private providers is open to doubt as they currently operate in elderly care on low margins, utilizing zero hour contracts and paying less than minimum wage for their staff (The Resolution Foundation, 2013). The withdrawal of the state from direct service provision in an era of austerity an personalisation, as with earlier regimes of market reform characterised by NPM, continues to raise concerns regarding sustainability of providers, the efficacy of user choice and the employment conditions of workers providing services.

\section{REFERENCES}

Alcock, P (2012) “Big Society - contradiction or con trick?”, Policy and Politics, 40 (1), 149-150.

Bach, S (2012) "Shrinking the state or the Big Society? Public service employment relations in an era of austerity", Industrial Relations Journal, 43, 5, 399-415. 
Bach, S and Bordogna, L (2011) Varieties of new public management or alternative models? The reform of public service employment relations in industrialized democracies, International Journal of Human Resource Management, 22 (11): 2281-94.

Bach, S and Kessler, I (2012) The Modernisation of the Public Services and Employer Relations: Targeted Change, Palgrave, Macmillan, Basingstoke.

Baines, D (2004) 'Caring for nothing. Work organisation and unwaged labour in social services", Work, employment and society, 18 (2), 267-295.

Bartels, P.R and Cozzi, G (2013) “The Big Society”, Public Expenditure and Volunteering", Public Administration Review, 77 (2), 340-351.

Baxter, K Wilberforce, M and Glendenning, C (2010) 'Personal Budgets and the Workforce Implications for Social Care Providers: Expectations and Early Experiences', Social Policy and Society, 10 (1): 55.

Blond, P (2010) Red Tory (London, Faber and Faber).

Cappelli, P (1999) The New Deal at Work: Managing the Market Driven Workforce, Harvard Business School Press, Harvard.

Cappelli, P (2012) 'Book Review: Market, Class and Employment', Work and Occupations 39 (1): 107-09.

Civil Exchange, (2013) The Big Society Audit 2013, December, London.

Cunningham, I (2008) Employment Relations in the Voluntary Sector, London: Routledge.

Cunningham, I and James, P (2009) "The outsourcing of social care in Britain: what does it mean for the voluntary sector workers?", Work, employment and society, 23, (2), 363 -375 .

Cunningham, I and James, P (2014) "Public Service Outsourcing and its 
Employment Implications in an Era of Austerity: The Case of British Social Care", Competition and Change, 18, (1), 1-19.

Cunningham, I and Nickson, D (2011) “A Gathering Storm? Re-tendering and the Voluntary Sector Workforce”, International Journal of Public Sector Management, 662-673.

Danson, M and Whittam, G (2011) “Scotland's Civic Society v England's Big Society? Roles of the VCS in Public Service Delivery”, Social Policy and Society, 10 (3), $353-363$.

Duffy, S, Waters, J and Glasby, J (2010) 'Personalisation and adult social care: future options for the reform of public services', Policy and Politics, 38 (4): 493-508.

Ellis, K (2007) 'Direct Payments and Social Work Practice: The Significance of 'Street-Level Bureaucracy’ in Determining Eligibility', British Journal of Social Work, 37, 405-22.

Evans, B. and Shields, J. (2002) 'The Third Sector: Neo-liberal Restructuring, Governance and the Re-making of State-Civil Society Relationships', in C. Dunn (ed.) The Handbook of Canadian Public Administration Toronto: Oxford University Press: 236-258.

Flecker,J, Holtgrewe,U, Schönauer, A (FORBA), Gavroglou, S (KEKMOKOP) (2009), Value chain restructuring and company strategies to reach flexibility, European Commission, Brussels.

Hood, C (1991) ‘A Public Management for All Seasons’, Public Administration, 69 (1), 1-13.

Leece, J (2010) "Paying the piper and calling the tune: Power and the direct payment relationship", British Journal of Social Work, 40 (1), 188-206.

Levitas, R, (2012) “The Just's Umbrella: Austerity and the Big Society in Coalition Policy and Beyond", Critical Social Policy, 32 (3), 320-342. 
Lowndes, V and Pratchett, L (2012) "Local Governance under the Coalition Government: Austerity”, Local Government Studies, 38 (1), 21-40.

McGovern, P, Hill, S, Mills, C and White, M (2007), Market, Class and Employment, Oxford University Press, Oxford.

Needham, C (2011) Personalising Public Services: Understanding the personalisation narrative, Policy Press, University of Bristol, Bristol.

The Resolution Foundation (2013) Does it pay to care? Under-Payment of the National Minimum Wage in the Social Care Sector, London.

Rubery, J and Urwin, P (2011) 'Bringing the employer back in: why social care needs a standard employment relationship', Human Resource Management Journal, 21 (2): 122-37.

Sage, D (2012) "A challenge to liberalism? The communitarianism of the Big Society and Blue Labour", Critical Social Policy, 32 (3), 365-82.

Sennett, R (1999) The Corrosion of Character: The Personal Consequences of Work in the New Capitalism, W.W Norton and Company, New York and London.

Shields, J (2014) “Constructing and 'Liberating' Temporariness in the Canadian Nonprofit Sector: Neoliberalism and Nonprofit Service Providers”. In Liberating Temporariness? Migration, Work and Citizenship in and Age of Insecurity. Robert Latham, Valerie Preston and Leah Vosko, eds. Montreal: McGill-Queen's University Press, , 255-281.

Sherman, J (2013) "The Big Society is dead, charities tell Cameron", The Times, January $7^{\text {th }}$, http://www.thetimes.co.uk/tto/news/politics/article3649734.ece. Accessed $1 / 05 / 2013$

Sullivan, H (2012) “A Big Society needs an active state”, Policy and Politics, 40 (1), $145-48$.

Thompson, J. A and Bunderson, P (2004) "Violations of principle: Ideological currency and the psychological contract", Academy of Management Review, 28 (4), 571-586. 
Peer-reviewed, accepted author manuscript of the following article: Cunningham, I. (2015). Austerity, personalisation and the degradation of voluntary sector employment conditions. Competition and Change, 19(3), 228-245. 10.1177/1024529415580261 